\title{
Rehabilitation in adult scoliosis: selected case series illustrating options for complexities associated with adult scoliosis
}

\author{
Cindy Marti, Michele Romano
}

From 7th International Conference on Conservative Management of Spinal Deformities

Montreal, Canada. 20-22 May 2010

Adults with scoliosis often present with multiple complications and co-morbidities affecting their quality of life. The primary source of pain and dysfunction may or not be directly related to the scoliosis but may be related to secondary or tertiary problems. Success for conservative treatment in adults with scoliosis hinges on the clinician's ability to systematically identify direct and indirect biomechanical contributors to pain and dysfunction, and then subsequently develop "bullet-point" treatment strategies to address the identified deficits, all under the umbrella of the "big picture" of the scoliosis. The resultant multi-faceted approach is often very individualized and - while the personalized care may yield good individual outcomes - it makes for challenging research. This being said, we believe that case histories with good outcomes can plant seeds for larger studies that can germinate and bloom into exciting options for adults with scoliosis.

We will present a series of individual case histories illustrating positive outcomes of conservative management with for adults with scoliosis. We chose to present some "non-classic" cases to illustrate that in adult scoliosis - like in life - the picture is usually complicated. We hope the case histories may inspire the audience to:

1. be expansive and creative in their evaluation and treatment of adults with scoliosis

2.generate ideas for larger studies evaluating conservative treatment in adults with scoliosis

Our own cases, as well as cases from other colleagues, will address patients with a mixture of problems including:

1.pain

2.respiratory dysfunction

3.lateral segmental olisthesis

4.Sagittal plane configuration

5.Frontal and sagittal plane imbalance

6.Curve progression

7.recurring rib fracture

8.progressive spinal deformity in adulthood

Our interventions are individualized to the patients and include:

1.manual therapy

2.orthopedic exercise

3.SI joint belt

4.identification and correction of leg length discrepancy

5.brace using TLSO

6.Specific exercises according to Barcelona-Schroth, SEAS, and others

Our outcomes have been measured by one or more of the following:

1. Oswestry Disability Index (ODI)

2. Visual Analog Scale (VAS)

3. Quality of Life Profile for Spinal Deformities (QLSPD)

4. Cobb Angle

5. Surface topography 
Although we are not all research facility, we hope our clinical case series may be a resource for ideas to further the systematic study of rehabilitation for adults with scoliosis.

Published: 10 September 2010

doi:10.1186/1748-7161-5-S1-050

Cite this article as: Marti and Romano: Rehabilitation in adult scoliosis: selected case series illustrating options for complexities associated with adult scoliosis. Scoliosis 2010 5(Suppl 1):O50.

Submit your next manuscript to BioMed Central and take full advantage of:

- Convenient online submission

- Thorough peer review

- No space constraints or color figure charges

- Immediate publication on acceptance

- Inclusion in PubMed, CAS, Scopus and Google Scholar

- Research which is freely available for redistribution

Submit your manuscript at www.biomedcentral.com/submit 